\title{
Study on process evaluation and early warning technology of 35 kV and above power grid infrastructure project
}

\author{
Qian Gao ${ }^{1 *}$, Wei Feng ${ }^{2}$, Xin Zhao ${ }^{2}$, Junyi Yang ${ }^{1}$, Yu Hong ${ }^{1}$, Jie Tang ${ }^{2}$, Qian $\mathrm{Wu}^{2}$ \\ ${ }^{1}$ State Grid Jiangsu Electric Power Co., Ltd., Nanjing, Jiangsu, 210024, China \\ ${ }^{2}$ Taizhou Power Supply Branch of State Grid Jiangsu Electric Power Co., Ltd, Taizhou, Jiangsu, 225300, China
}

\begin{abstract}
The management requirements of internal quality and efficiency improvement of State Grid Corporation and the internal and external environment of strengthening external supervision have put forward higher requirements for investment management, and also emphasized the accuracy and authenticity of investment execution. However, at present, the company's investment management lacks the analysis tools of investment execution. Therefore, this project constructs the whole process early warning and evaluation model of investment, realizes three functions of "advance" warning, "pre-warning" before the arrival of the milestone node plan time, and the "after the event" implementation evaluation, so as to effectively monitor the implementation of the whole process of investment management and improve the overall investment of the company Capital level.
\end{abstract}

\section{Research background}

In recent years, with the increase of power grid investment scale and the change of investment supervision, the power grid investment management is facing great challenges. The lack of supervision tools for the whole process of power grid investment makes it difficult to effectively supervise the investment plan and meet the internal needs of the power grid company's investment lean management. In order to improve the prediction and pre control ability of lean management in the whole process of the project, and improve the scientificity of the control objectives and the effectiveness of the path, it is necessary to carry out the whole process model analysis of investment.

\section{Research objectives and ideas}

This project takes the power grid infrastructure projects of $35 \mathrm{kV}$ and above as the research object, takes the whole process of investment management as the main line, and combs the key links of investment process management and the key contents of key links. Based on the focus of business, the "pre-warning" model of investment execution and the "post event" evaluation model of investment execution are constructed. Through the reminder and early warning before the arrival of the milestone node plan time, and the index system of post implementation evaluation, the whole process of investment implementation can be effectively monitored, and the overall investment level of the company can be improved.

The main research content of this subject includes two parts: one is the research on the "pre-warning" model of investment plan implementation; the other is the research on the "post event" evaluation model of investment plan implementation. Among them, the "pre-warning" model includes two functional modules: advance reminder and advance warning. The specific research ideas are as follows:

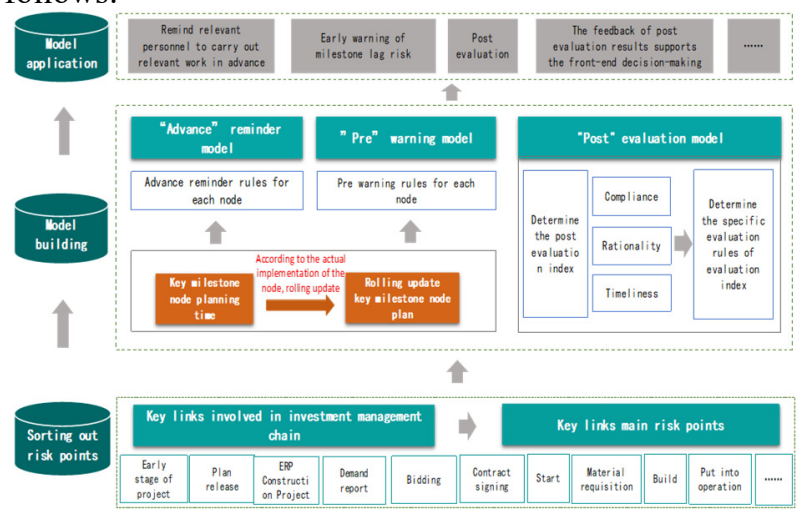

Fig1. Research ideas of pre warning and evaluation

\section{Establishment of process evaluation and early warning rules for power grid infrastructure projects}

\subsection{Pre-warning rules for investment execution}

(1) Rules for advance reminder of investment execution Based on the time plan of key milestone nodes in the process of investment and implementation of power grid infrastructure projects, according to the length of the time from the current time to the planned time, combined with the business conditions to be met for each node 
implementation, this paper gives the reminder suggestions of "mild reminder, moderate reminder and severe reminder" to remind business personnel to carry out relevant work in time, so as to ensure that the project is scheduled according to the milestone node Orderly progress.

Take the project start node as an example to explain the advance reminder rules:

Give a slight prompt $\mathrm{X}+\mathrm{N} 1+\mathrm{N} 2$ days before the project commencement plan time to remind the business personnel to handle the necessary procedures for commencement in time;

Give a moderate prompt in the first $\mathrm{X}+\mathrm{N} 1$ days, the operator should be reminded to handle the necessary procedures for commencement in time;

Severe reminder $\mathrm{X}$ days before, remind the business personnel to go through the necessary procedures in time; if the node has been completed, it will not be prompted any more. The principle of prompting in other stages is the same as that in this stage.

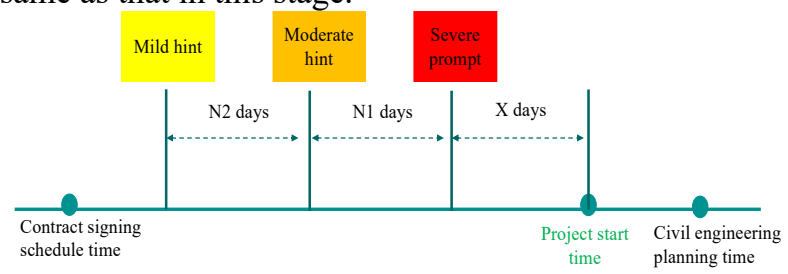

Fig2. Schematic diagram of advance reminder rules (taking project start node as an example)

(2) Pre-warning rules for investment execution

If the actual execution time of a node of the investment management milestone is later than the planned time, it may affect the planned time of the subsequent associated nodes. The planned time of the subsequent nodes needs to be updated on a rolling basis. At the same time, the associated node that updates the planned time will be alerted to the degree of lag.

(1) Judge the advance and lag of the actual implementation of the current key node

If the actual execution time of the current node is earlier than the planned time, the early execution of the current node will not affect the subsequent associated nodes, and there is no need to scroll the planned time of the subsequent associated nodes;

If the actual execution time of the current node is later than the planned time, it is necessary to determine whether the actual execution time of the current node will affect the subsequent associated nodes, and then perform the second step.

(2) Judge whether the time interval between the actual execution time of the current key node and the planned time of the subsequent associated nodes is within a reasonable time interval

If the time interval between them is within a reasonable interval, there is no need to scroll the planning time of the subsequent associated nodes;

If the time interval between the two is too short to meet the reasonable time interval, that is, the reserved time is not enough to support the subsequent related links to carry out business activities, the subsequent associated nodes need to be updated in a rolling manner.
Update time $=$ the planned time of this node + the lag time of the previous related node (the actual time of the previous related node - the planned time of the previous related node), and so on.

The pre-warning rules of key nodes in the whole process of investment execution are shown as follows:

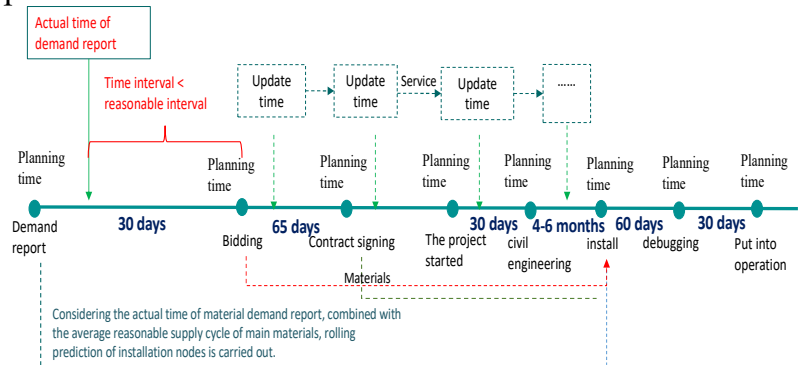

Fig3. Pre warning rules of key nodes in the whole process of investment execution

\subsection{Post evaluation rules of investment execution}

(1) Determine indicators

Through sorting out the key business involved in the whole process of investment and implementation of $35 \mathrm{kV}$ and above power grid infrastructure projects, the index system is determined from the following three aspects:

- Compliance index: it reflects whether the implementation process of power grid investment conforms to the national policies and regulations or the system standards of power grid company.

- Timeliness index: it reflects whether the actual business implementation is carried out as scheduled according to the milestone plan.

- The rationality index: it reflects whether the investment implementation process is reasonable according to the management requirements of each specialty or the reasonable business logic among the specialties.

Specific indicators are set as follows:

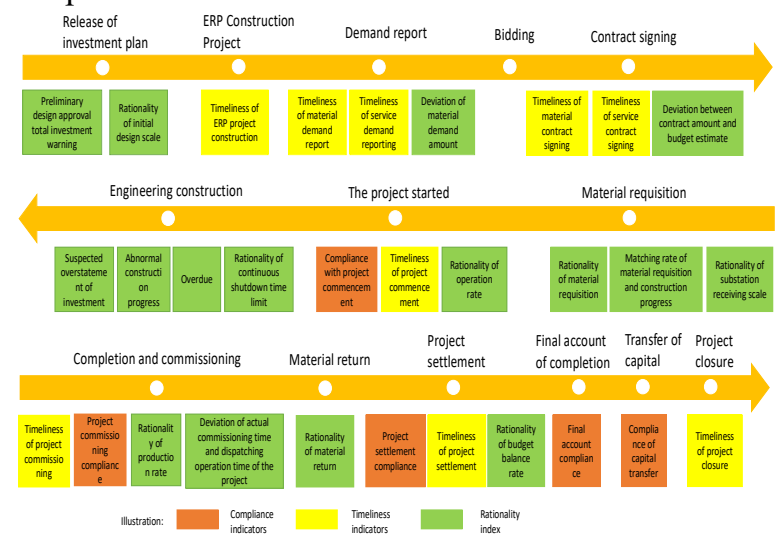

Fig4. Post evaluation index of investment execution

(2) Set scoring rules

On the basis of the above indicators, in order to unify the results of different types of indicators to facilitate the overall evaluation of the project, the membership function 
is used to calculate the index score, that is, a standard value range is set for each index, and the index score is calculated according to the degree of the actual value of the index deviating from the standard value, so that the score results of different indicators can be unified as $[0,1]$. There are three types of membership functions in the range of values and membership functions.
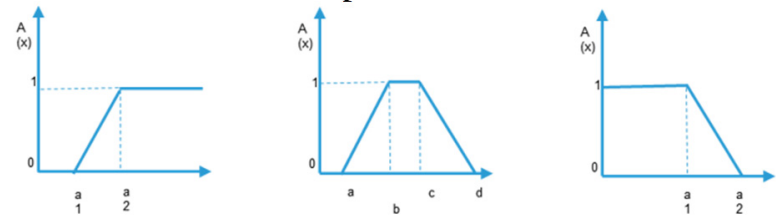

Fig5. . Membership function diagram (from left to right, it is the upper Jung type function, the intermediate type function and the lower Jung type function)

\section{Demonstration and analysis}

(1) Project level analysis

Taking the $220 \mathrm{kV}$ substation project of a city company as an example, the feasibility study of the project has approved a transformation capacity of $180000 \mathrm{KVA}$ and a total investment of 20.66 million yuan. As of the current time (October 14, 2020), the project is in the material demand reporting stage. The early warning and evaluation of investment implementation process are shown in the following figure:

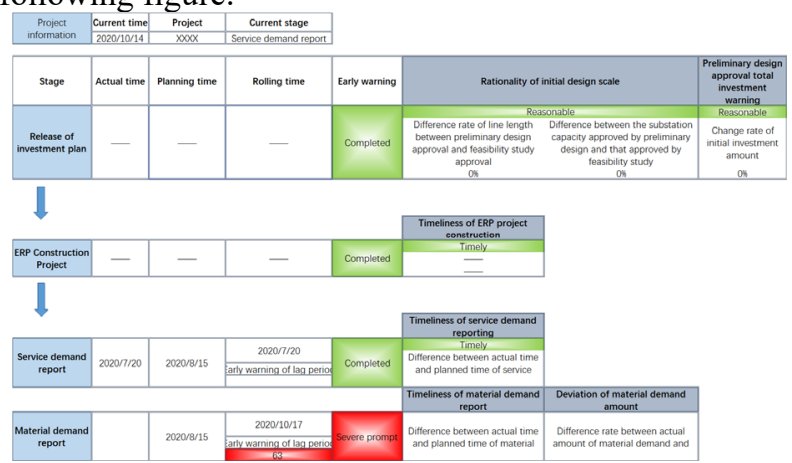

Fig6. Example of early warning and evaluation results for investment implementation of a $220 \mathrm{kV}$ substation project

Note: the above figure only intercepts part of the investment execution process, and the figure of the subsequent non executed links is not intercepted.

Early warning: the project is currently in the material demand reporting stage, and has missed the deadline of the planned bidding batch. According to the updated rolling time, it can be seen that the demand submission time of the next batch is October 17, 2020. The current time is close to this time, and it has been in a severe prompt state to remind relevant business personnel to carry out work in time.

Evaluation: the evaluation results of the three key nodes of the project are as follows:

Release node of investment plan: since the difference rate of substation capacity between preliminary design approval and feasibility study approval is $0 \%$, the evaluation result of rationality index of preliminary design scale is reasonable; as the change rate of initial design investment amount is $0 \%$, the early warning index of total investment in preliminary design approval is reasonable.
ERP project construction node: ERP project construction is timely.

Service demand reporting node: service demand reporting is timely.

(2) Unit level analysis

On the basis of the above project level indicators early warning and evaluation, according to the multidimensional attributes of the project (city, voltage level, construction nature, key special types, etc.), pre-warning and post evaluation are displayed to support the management needs of different management levels. As shown in the figure below, the results of the model at the level of local and municipal companies are shown, showing the early warning situation and the overall evaluation of investment implementation of local companies.

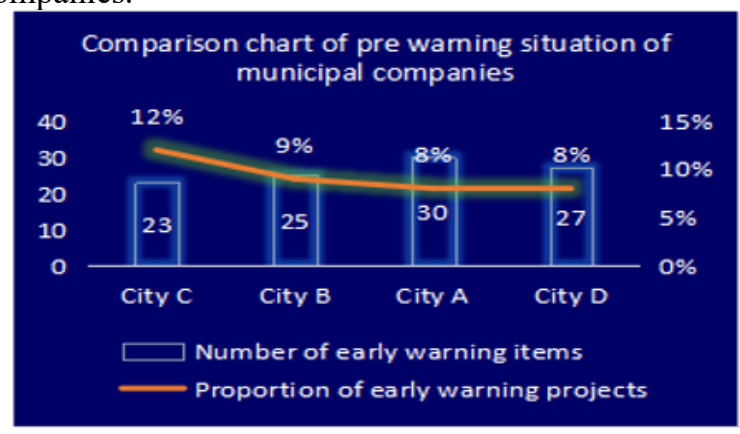

Fig7. The results of early warning of unit level investment execution

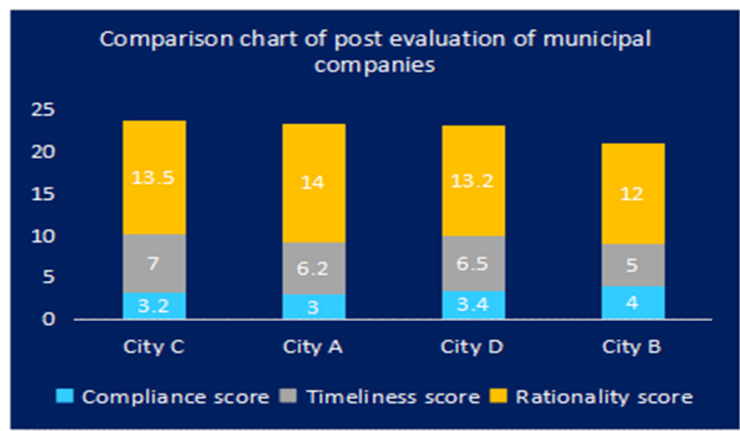

Fig8. Comparison chart of part evaluation of municipal companies

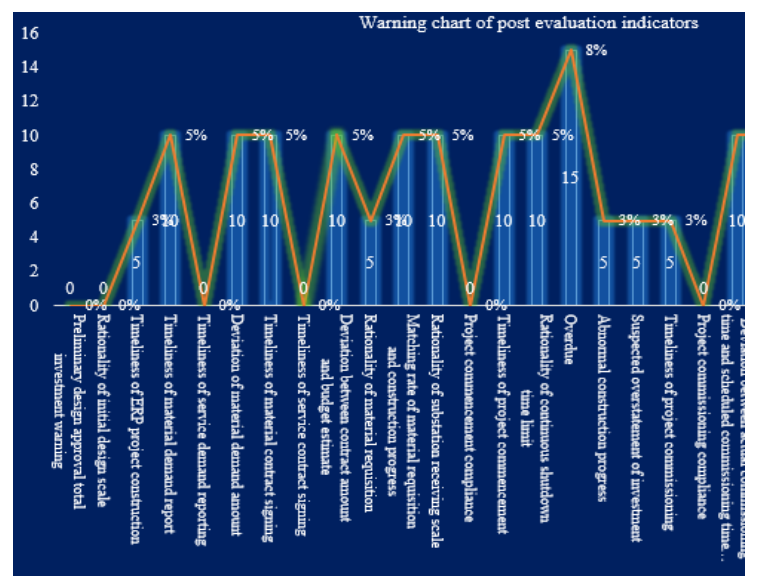

Fig9. The results of evaluation of unit level investment execution

Figure 7 early warning: it shows the proportion of prewarning items and early-warning projects of Companies in different cities. 
It can be seen from the figure that the early warning proportion of projects in city A and city D is relatively low, both $8 \%$; the early warning proportion of projects in City $\mathrm{C}$ is high, which is $12 \%$.

Suggestions: City $\mathrm{C}$ should strengthen the monitoring of key nodes of investment implementation, and complete the preliminary procedures of business development of this node before the planned time of each node, so as to ensure the normal implementation of investment and reduce the proportion of early-warning projects.

Figure 8 evaluation: it shows the scores of compliance, rationality and timeliness indicators of Companies in different cities and cities, and ranks them from high to low, showing the ranking of comprehensive scores in the whole process of investment capital implementation of local companies in provincial companies.

It can be seen from the figure that the comprehensive score of City $\mathrm{C}$ is higher than that of city $\mathrm{B}$, especially the timeliness score and rationality score are low. For the companies with low ranking score, the power grid investment management of the company should be strengthened.

Figure 9 evaluation: it shows the evaluation results of indicators involved in each link of investment implementation.

According to the number and proportion of early warning indicators of different evaluation indicators in the implementation process of the investment index of local and municipal companies, the company should pay attention to the indicators with more early warning proportion, so as to improve the rationality, compliance and timeliness of the implementation of the link.

\section{Conclusion}

This project takes the power grid infrastructure projects of $35 \mathrm{kV}$ and above as the research object. By combing the key business contents of the milestone nodes in the whole process of investment management, the monitoring indicators and early warning rules of each stage of the project are clarified, which provides technology for timely and accurate positioning of abnormal conditions of distribution network projects, improving the efficiency of feedback and correction, accelerating the transformation of project investment benefits, and improving the level of investment lean management.

\section{References}

1. Wang, L, Peng, D.X., Wu, H.L. (2020) Research on the evaluation system of power grid enterprise investment management and control in the whole process -- multi attribute decision analysis based on binary semantics. Price theory and practice, (05): 106109.

2. Ji, X.J., Wang, Y.Q. (2018) Investment risk assessment and coping strategies of power grid companies under the background of power reform. Power grid and clean energy, 34 (05): 6-12.

3. Zhang, D.E. (2018) Suggestions on the whole process control of power grid construction project investment. Modern economic information, (23): 313+315.

4. Yang, L. (2015) Research on the post evaluation system of the whole process of power grid investment projects. Science and technology and enterprises, (14): 27. 